\title{
The impact of cyber dating abuse on self-esteem: The mediating role of emotional distress
}

\author{
Kaitlin Hancock, Haley Keast, \& Wendy Ellis \\ King's University College at Western University, London, ON, Canada
}

\begin{abstract}
This study examined how emotional distress mediated the relationship between cyber dating abuse and selfesteem. Participants were 155 undergraduate students (105 females; 50 males) ranging from 17 to 25 years old $(M=19.38, S D=1.65)$ with dating experience and a minimum relationship duration of 3 months. Self-report assessments of cyber dating abuse, self-esteem, and emotional distress from the relationship were completed. Mediation analysis using multiple regressions revealed a full mediation model. Cyber dating abuse predicted lowered self-esteem and greater emotional distress. However, when emotional distress was entered as a predictor of self-esteem, cyber dating abuse became non-significant, indicating full mediation. Early-onset of dating was also a risk factor for cyber dating abuse and emotional distress. Few gender differences were evident. These findings add to the growing body of evidence on the negative effects of cyber dating abuse and suggest that distressing emotional reactions may underlie the deleterious consequences of this form of abuse.
\end{abstract}

Keywords: Adolescent dating relationships; cyber dating violence; self-esteem; emotional distress; emerging adulthood

\section{Introduction}

Romantic relationships commonly begin in early adolescence and increase in significance and stability over time (Smetana, Campione-Barr, \& Metzler, 2006). Reports indicate that by the end of high school, over $75 \%$ of emerging adults are involved in romantic relationship (Smetana et al., 2006). The development of romantic relationships is commonly linked to positive adjustment and increased levels of perceived support (Collins, Welsh, \& Furman, 2009). Unfortunately, not all individuals receive such benefits from their intimate relationships. Dating abuse is a common experience among emerging adults that has significant consequences for mental and physical well-being (Liu, Yu, \& Ma, 2014). In particular, negative effects of dating abuse have been found on an individual's self-worth (Rill, Baiocchi, Hopper, Denker, \& Olson, 2009). According to the National Centre of Injury Prevention and Control (2016), dating abuse involves using psychological, physical, emotional, and/or sexual behaviors to gain and maintain power and control over one's partner in a romantic relationship.

The pervasive use of technology among youth has further complicated abusive behaviors in the dating context. Cyber dating abuse is defined as abuse, threats, or harassment that is digitally perpetrated within a romantic relationship through technology or other forms of new media such as social network sites, text messages, or emails (Zweig, Dank, Yahner, \& Lachman, 2013). Research examining cyber dating abuse has increased considerably in recent years, but to date, most studies are descriptive in nature and there remain many unanswered questions about the effects of cyber dating abuse on adjustment. The goal of the present study was to investigate the relationship between cyber dating abuse and self-esteem in a sample of emerging adults (i.e., those within the period from the late teens through the twenties; Arnett, 2000). More specifically, our goal was to 
examine how reactions of emotional distress could mediate or explain the expected relationship between the experience of cyber dating abuse and decreased self-esteem (Katz, Arias, \& Beach, 2000; Rill et al., 2009).

Traditionally, definitions of dating abuse have included physical, psychological or sexual harm occurring between two people in a romantic relationship (Iconis, 2013; Stader, 2011). Researchers propose that the goal of this abuse is often to manipulate the victimized partner, for example, by limiting the victim's communication or outside resources, forcing them to rely on the perpetrator for the fulfillment of their needs (Eshelman \& Levendosky, 2012). Cyber dating abuse overlaps with other forms of dating violence, particularly psychological and emotional abuse; perpetrators who engage in these forms of offline abuse are also more likely to engage in online dating abuse (Borrajo, Gamez-Guadix \& Calvete, 2015). Examples of cyber dating abuse include: sending threatening e-mails, posting hostile messages on the Internet, and obtaining personal information about the victim without his or her consent such as from emails or texts. Cyber dating abuse is distinguished from traditional violence in two primary ways, both associated with easier perpetration (Melander, 2010). First, technology is quite accessible and relatively easy to use, making these behaviors quick and easy to execute. Second, the electronic medium allows the perpetrator to easily turn private matters public, thus intensifying the victim's feelings of vulnerability. This vulnerability is further amplified by the inescapable nature of cyber dating abuse, due to the allowance of constant communication, easier monitoring of a partner's whereabouts, and added methods of privacy invasion (Patchin \& Hinduja, 2010; Wright, 2015). These unique characteristics suggest that cyber dating abuse may be more harmful than other types of dating abuse because of the perpetual accessibility technology offers. In recent studies, prevalence rates as high as $50 \%$ have been reported for cyber dating abuse (Borrajo et al., 2015).

Exposure to dating violence in all forms during emerging adulthood is associated with a wide range of negative outcomes involving diminished relationship quality (Marcus, 2004) and individual adjustment, including low selfesteem (Katz, et al., 2000), substance use (Eshelman \& Levendosky, 2012), school dropout (Kaukinen, 2014), and feelings of depression and anxiety (Hanson, 2002). To understand these negative outcomes in greater detail, researchers have often sought to explore the impact of specific types of dating violence (e.g., Ellis, Crooks, \& Wolfe, 2009). However, the victims of dating violence typically experience a combination of two or more types of emotional, physical, psychological, or sexual abuse. Furthermore, those who experience multiple sources have the highest rates of mental health symptoms (Eshelman \& Levendosky, 2012). Cyber dating abuse specifically, tends to coexist with other forms of dating aggression and is highly correlated with experiences of psychological abuse (Temple et al., 2016; Zweig, Lachman, Yahner, \& Dank, 2014). Therefore, an assessment of cyber dating abuse likely implicates other abusive behaviors. The relative effect of cyber dating abuse on adjustment is largely unknown at this time; however, in one study, adolescents reported psychological aggression to be more unpleasant than physical aggression (Jouriles, Garrido, Rosenfield, \& McDonald, 2009).

One consistent finding in research demonstrating effects of dating abuse on adjustment is the negative impact of abuse upon an individual's self-esteem (Göncü \& Sümer, 2011; Katz et al., 2000; Rill et al., 2009; Robinson \& Cameron, 2012). Using traditional definitions of physical, emotional, and sexual dating abuse, studies have found lowered self-esteem, increased feelings of inferiority, and self-defeating beliefs among victims (Göncü \& Sümer, 2011; Longmore \& Demaris, 1997; Sawangchareon et al., 2013). It has also been noted that low self-esteem is linked to low satisfaction in romantic relationships and less commitment to one's partner (Downey \& Feldman, 1996; Katz et al., 2000; Rill et al., 2009). An individual's self-esteem is likely tied to their intimate relationships because of the fundamental need for positive acceptance (Leary \& Baumeister, 2000). According to sociolocation theory (Burton, Halpern-Felsher, Rehm, Rankin, \& Humphreys, 2013), dating and other types of relationships contribute to an individual's "sociolocation", defined as the "social self-location" or "self-identification and recognition of social integration through relationship" (Burton et al., 2013, p. 804). From an evolutionary perspective, humans who belonged to social groups were more likely to survive and reproduce. Self-esteem is often defined as an internal representation of social value. Studies show that a partner's evaluations clearly affect one's own self-evaluations (Leary, Tambor, Terdal, \& Downs, 1995). As such, individuals are likely to collect self-perceptions from patterns of interactions between themselves and their romantic partners. According to this view, individuals are constantly assessing their perceived rejection or acceptance by their partners.

According to Rusbult's (1980) investment model of relationships, commitment to a relationship is affected by the level of satisfaction, investment, and attractiveness of other alternatives. This suggests that higher rates of 
satisfaction and investment, and lower rates for attractiveness to other alternatives predict a more committed relationship. This model illustrates the stability of some abusive relationships. A study conducted with abused women (Rusbult \& Martz, 1995) found that feelings of commitment were higher for women who were heavily invested in their relationship (being married), had lower economic alternatives (not having a safe place to live), and had experienced less dissatisfaction within the relationship (experienced less severe abuse). In a like manner, people who engage in cyber dating abuse may have heavily invested in the relationship and may not consider cyber dating abuse a serious offense.

When involved in abusive dating relationships, victims often experience persistent jealous reactions, anger, and a lack of proper conflict resolution strategies (Korchmaros, Ybarra, Langhinrichsen-Rohling, Boyd, \& Lenhart, 2013; Orpinas, Hsieh, Song, Holland, \& Nahapetyan, 2013). In terms of cyber dating abuse, victims experience behaviors from partners that violate their trust, make them feel untrustworthy or are inconsiderate. For instance, hacking into emails or the feeling of being monitored could result in feelings of inferiority. Over time, these exchanges may lead to diminished feelings of worth, distress or fear, and lower self-esteem. Emotional distress in the relationship context involves feeling unworthy of the partner's love and respect. In the present study, we measured emotional distress reactions including guilt, anger, and hurt experienced in response to their dating partners. According to the above theoretical explanations of self-esteem, individuals will gauge these emotional reactions and formulate perceptions that they are an incompetent partner, leading to diminished selfesteem.

A secondary goal of the present study was to assess gender differences in cyber dating aggression. In traditional assessments of dating violence prevalence rates, mixed findings have been noted. One study reported a higher proportion of women perpetrating verbal and physical aggression towards their partners (Munoz-Rivas, Gomez, O'Leary, \& Lozano, 2007). In numerous other studies, however, females reported being victimized more than males (Eshelman \& Levendosky, 2012; Hanson, 2002; Iconis, 2013). Few studies have examined rates of cyber dating aggression; however, a study by Burke, Wallen, Vail-Smith, and Knox (2011) showed that females tend to perpetrate this cyber aggression more than males, especially in terms of e-mail monitoring. Similarly, Zweig et al. (2013) found that females perpetrated more non-sexual cyber dating abuse than did males. Dick et al. (2014) noted that females also reported more cyber dating abuse victimization than males. However, when it comes to sexual dating abuse, both traditional and cyber, males report as much as twice the amount of female perpetration (Foshee, 1996; Zweig et al., 2013).

In summary, the goals of the present study were to: a) examine the relationship between cyber dating abuse and self-esteem; b) examine emotional distress responses as a mediator of the relationship between cyber dating abuse and self-esteem; and c) examine rates of cyber dating abuse and possible gender differences. More specifically, it was hypothesized that emotional distress would be a mediator of cyber dating abuse in negatively predicting self-esteem. Survey data was collected from a sample of first year university students to address these goals.

\section{Method}

\section{Participants and Procedure}

A total of 155 undergraduate students (105 females; 50 males), ranging from 17 to 25 years of age $(M=19.38, S D$ $=1.65)$, participated in this study. Female participants ranged from 18 to 25 years of age $(M=19.17, S D=1.58)$, while males ranged from 17 to 25 years of age $(M=19.96, S D=1.98)$. Participants were recruited from Introductory Psychology classes in a Canadian University. Introductory Psychology students received bonus marks for completing a related assignment. The participants included only those who were currently in a dating relationship or those who had a recent dating relationship within the past year, and both with a minimum relationship duration of three months. If students did not meet these eligibility requirements they had the opportunity to participate in other studies where they would receive the same amount of bonus marks.

The study was approved by the University's Ethics Review Committee. Participants were recruited by an online system directed towards Introductory Psychology students. The online system provided students with the title of 
the study, a description of the tasks required of the participants, and the approximate length of time it would take to complete the study.

Upon registering for the study, participants were sent an e-mail containing a link to the study and an electronic copy of the research participation assignment. Participants followed the link and logged-in to the survey by using their student username and password. The data was not connected to their student username. Consent was administered to the participants electronically, where they were assured that their participation was confidential and anonymous, and that they could withdraw from the study at any time while still receiving credit for their participation. Upon completion of the study, debriefing forms appeared on the final page of the survey which included the purpose of the study, the researchers' contact information, and the contact information of the city's Distress Centre. The survey took approximately 15 minutes to complete.

\section{Measures}

Participants first answered demographic questions (e.g., age, gender), including four questions about their dating habits; these questions pertained to their sexual orientation, the length of their most recent relationship, the total number of relationships in their lifetime, and the age at which they began dating.

Cyber dating abuse. The 14 cyber dating abuse questions were taken from Picard (2007). Two items pertaining to sexual cyber dating abuse were excluded as it was thought that they might cause the participants significant distress. The items focused on various forms of abuse occurring within the past year (e.g., threats, humiliation, harsh comments) committed through a variety of social mediums (e.g., texts, e-mails, chats, social networks). Responses were made on a likert-type format consisting of four anchors: "never", "rarely", "sometimes", and "often". Items and participants' responses can be found in Table 1. For the purposes of the present study the participants' responses were averaged across all 14 items. The 14 items pertaining to cyber dating abuse had a Cronbach's alpha of .79.

Self-esteem. Using the Rosenberg (1965) Self-Esteem Scale, participants rated 10 items on a 4-point likert-type scale (e.g., "I feel that I'm a person of worth, at least on an equal plane with others" and "All in all, I am inclined to feel that I am a failure"). Response options were "Strongly disagree", "Disagree", "Agree", and "Strongly agree". Five items were reverse-scored, as they are negative in valence and the 10 items were averaged to create a final score. The scale had a Cronbach's alpha of .88.

Emotional distress response. Participants' emotional distress in the context of their dating relationship was measured using 7 items taken from the Quality of Relationships Inventory (Pierce, Sarason, \& Sarason, 1991). Seven items were selected that specifically reflect the participant's emotional response or pattern of emotional reactions within the relationship. Example items include: "How angry does this person make you feel?"; "How upset does this person make you feel?"; and "How much does this person make you feel guilty?". The scoring for the questionnaire is based from a 5 point likert-scale with anchors including "never", "hardly ever", "sometimes", "many times", and "most of the time". The 7 items were averaged to create one score for this variable. The Cronbach's alpha for this revised scale was .87.

\section{Results}

\section{Analysis of Measures}

First, all measures were examined with a confirmatory principal components analysis to determine the dimensionality of our scales.

The factorability of the 14 item Cyber Dating Abuse Scale was examined using principal component analysis with Varimax rotation. The analysis extracted four factors, accounting for 33\%, 13\%, $8 \%$ and $7 \%$, respectively. There were 10 items extracted for the first component. However, it was also noted that all 14 items correlated significantly with at least one other item, suggesting it was reasonable to use a unidimensional scale. Also, the Kaiser-Meyer-Olkin measure of sampling adequacy was .80 above the recommend value of .6 and Bartlett's test 
of sphericity was significant $\left(X^{2}=596.13, p<.01\right)$. All scores were averaged across the 14 items to yield a final score for each participant.

The factorability of the 10 item Self-Esteem Scale was also examined using principal component analysis with Varimax rotation. The analysis yielded a single factor and accounted for $51 \%$ of the variance. It was observed that 10 items correlated significantly with at least one other item, suggesting reasonable factorability. Also, the Kaiser-Meyer-Olkin measure of sampling adequacy was .88 above the recommend value of .6 and Bartlett's test of sphericity was significant $\left(X^{2}=725.60, p<.01\right)$. All scores were averaged across the 10 items to produce a final number for each participant.

The factorability of the 7 items for the Emotional Distress Response was also examined with a principal component analysis with Varimax rotation. This was a unidimensional scale and accounted for $57 \%$ of the variance. It was observed that 7 items correlated significantly with at least one other item, suggesting reasonable factorability. Also, the Kaiser-Meyer-Olkin measure of sampling adequacy was .86 above the recommend value of .6 and Bartlett's test of sphericity was significant $\left(X^{2}=525.83, p<.01\right)$. All scores were averaged across the 7 items to produce a final number for each participant.

\section{Descriptive Information on Participant's Dating Experiences}

The sample was first analyzed to determine information about the participants' dating experiences and identify any important covariates. Most participants reported that they started dating at age $14-16(63 \% ; M=15.49$ years, $S D=1.82$ ), with a range of 11-20 years of age. The majority of participants reported that they were involved in 13 relationships $(80 \% ; M=2.65, S D=1.76)$, with a range of $1-12$ relationships. Approximately $67 \%(105)$ of participants reported they were involved in an intimate relationship during the study, while 33\% (50) reported they were not. For those who were in a relationship, participants' reported that the length of their current relationship ranged from 3 months to 8 years $(M=21.70$ months, $S D=1.53)$ For those who were not in a relationship, participants reported that the length of their past relationship ranged from 3 months to 5 years ( $M$ $=13.90$ months, $S D=12.72$ ). The majority of the participants reported that they were involved in heterosexual relationships; 150 participants reported that they were involved in opposite-sex relationships, while 5 participants reported being in same-sex relationships.

\section{Frequencies of Cyber Dating Abuse Behaviors}

Participants reported the frequencies of being a target of cyber dating abuse on 10 items and are listed in Table 1. The most common behavior (77\%) involved participants receiving text messages from their partners checking up on them (e.g., where are you, what are you doing, who are you with). The second most common behavior (43\%) involved participants being shouted at by their partners over the phone. Ten percent of participants reported never to all items and $14 \%$ of the sample experienced 5 or more of the cyber dating abuse behaviors that were examined.

\section{Correlations and Gender Differences Among Variables}

Correlations were computed among self-esteem, dating experience and demographic variables (see Table 2). Both cyber dating abuse and the hypothesized mediator (emotional distress) were significantly correlated with self-esteem. Emotional distress and cyber dating abuse were both related to an earlier onset of dating and more frequent relationships. The number of total relationships was significantly correlated with the age of dating and length of relationships, such that participants who reported dating on-set at younger ages reported more, and longer relationships. These correlations did not differ significantly by gender.

There were no overall gender differences in the composite score for cyber dating abuse. However, t-tests were used to compare rates for each response item. Only one difference was found for the item "used your social networking site without your permission". More females (25\%; $M=1.28(.58)$ ) reported this behavior than males $\left(8 \% ; M=1.08(.28), t_{(153)}=2.99, p<.01, d=.48\right)$. 
Table 1. Frequencies of Reported Cyber Dating Abuse.

\begin{tabular}{lll}
\hline Behavior & Percentage (CI) \\
\hline $\begin{array}{l}\text { Received text messages from their partner checking up on them (e.g., where are you, what } \\
\text { are you doing, who are you with) }\end{array}$ & $78 \%$ & $(.72-85)$ \\
Partner shouted at you over the phone & $42 \%$ & $(.03-.12)$ \\
Partner made you feel afraid when they did not respond to cell phone calls, texts, postings & $18 \%$ & $(.10-.21)$ \\
on social networking page, or instant messages & & \\
Partner sent participant instant messages or chats that made you feel scared & $14 \%$ & $(.17-.18)$ \\
You had been harassed or put down by your partner on social networking websites & $15 \%$ & $(.07-.18)$ \\
You had been sent threatening text messages by your partner & $14 \%$ & $(.32-.48)$ \\
Partner used your social network account without permission & $14 \%$ & $(.01-.07)$ \\
Partner sent you so many messages (texts, emails, chats) that it made you feel scared & $14 \%$ & $(.01-.07)$ \\
Partner posted embarrassing photos or videos of you online & $12 \%$ & $(.07-.18)$ \\
Partner taken a video of you and sent it to his/her friends without your permission & $11 \%$ & $(.07-.18)$ \\
Partner spread rumors about you using a cell phone, IM, Webchat or social networking site & $8 \%$ & $(.02-.09)$ \\
Partner wrote nasty things about you on his/her profile page & $4 \%$ & $(.01-.06)$ \\
Partner created a profile page (like Facebook, MySpace or YouTube) about you knowing it & $3 \%$ & $(.06-.16)$ \\
would upset you & & $(.01-.07)$ \\
Partner threatened to harm you physically though a cell phone, text message or social & $3 \%$ & \\
networking page & &
\end{tabular}

Table 2. Means, standard deviations and correlations among self-esteem, cyber dating abuse, emotional distress and dating variables.

\begin{tabular}{lllllllll}
\hline & $\boldsymbol{M}(\boldsymbol{S D})$ & $\mathbf{1}$ & $\mathbf{2}$ & $\mathbf{3}$ & $\mathbf{4}$ & $\mathbf{5}$ & $\mathbf{6}$ & $\mathbf{7}$ \\
\hline 1. Self-Esteem & $2.96(.37)$ & & & & & & & \\
2. Emotional Distress & $3.80(.63)$ & $-.38^{* *}$ & & & & & & \\
3. Cyber Dating Abuse & $1.26(.28)$ & $-.16^{*}$ & $.48^{* *}$ & & & & & \\
4. Length of relationship & 19.02 months & .003 & .10 & -.10 & & & & \\
reported & $(16.61)$ & & & & & & & \\
5. Age of First Relationship & $15.64(1.69)$ & .07 & $-.21^{*}$ & $-.22^{* *}$ & $-.22^{* *}$ & & & \\
6. Total Number of & $2.47(1.47)$ & $-.17^{*}$ & $.18^{*}$ & $.16^{*}$ & $.16^{*}$ & $-.47^{* *}$ & & \\
Relationships & & & & & & & & \\
7. Age & $19.30(1.53)$ & .09 & -.09 & -.04 & $.29 * *$ & .17 & .09 & .09 \\
8. Gender & $1.31(.46)$ & $.29^{* *}$ & .10 & .12 & -.02 & .08 & .06 & $.20^{*}$ \\
\hline
\end{tabular}

Note: $N=153, * p<.05,{ }^{\star *} p<.01$

\section{Differences in Relationships Reported}

To determine if participants differed depending on their reported current relationship status, t-tests compared average levels of cyber dating abuse, emotional distress, and self-esteem between those who reported on their current dating relationship and those who reported on a previous dating relationship. As expected, participants who reported being involved in a current dating relationship had less cyber dating abuse $\left(M=1.18(.15), t_{(153)}=\right.$ 4.27, $p<.01, d=.72)$, lower emotional distress $\left(M=3.33(.57), t_{(153)}=4.84, p<.01, d=1.25\right)$, and higher selfesteem $\left(M=2.89(.34) t_{(153)}=-2.07, p<.05, d=.32\right)$ than those who were reporting about past relationships $(M s(S E s)=1.38(.38), 4.04(.53), 3.00(.38)$, respectively). Given these differences, all regression analyses were first tested with current relationship status as a covariate and as a moderator of cyber dating abuse and emotional 
distress. However, relationship status was not significant in any equation and all results remained identical and relationship status was subsequently removed from all analysis.

\section{Hypotheses}

The hypothesis of the present study was tested using multiple regression analysis in SPSS version 21 . To examine the possibility that emotional distress was a mediator of cyber dating abuse in predicting self-esteem, a series of regression analyses were first computed. As recommended by Baron and Kenny (1986), three regression analyses were performed following an examination of variable correlations. All variables in this study were significantly correlated and mediation testing was warranted (see Table 2). For the first regression, cyber dating abuse was regressed upon the criterion variable, self esteem (step 1). In the next regression equation, cyber dating abuse was entered as a predictor of emotional distress (step 2). According to Baron and Kenny (1986), if step 1 and 2 are significant, a mediation test is acceptable. For step 3, the mediator (emotional distress) and predictor variable (cyber dating abuse) were simultaneously regressed upon the criterion variable (selfesteem). If the relationship between the predictor and criterion variables was reduced to an effect of no significance while the relationship between the mediator and criterion remained significant, then a full mediation would be supported.

Hierarchal linear regression was used for each step in testing the mediation model. In each equation, age and gender were entered into the first block to control for these variables. To test for moderating effects of age and gender, interaction terms were created using recommendations from Aiken and West (1991) and entered in the final step of the third regression. There were no significant interactions between gender, age, and cyber dating abuse or gender, age and emotional distress in predicting self-esteem. Given no significant interactions were found, these variables were subsequently removed from equations.

Because the first two paths were significant, mediation analyses were tested using the PROCESS macro and bootstrapping method with bias-corrected confidence estimates (MacKinnon, Lockwood, \& Williams, 2004; Preacher \& Hayes, 2004). In the present study, the $95 \%$ confidence interval of the indirect effects was obtained with 5000 bootstrap samples (Preacher \& Hayes, 2008).

Step 1. The first regression analysis was computed to determine whether cyber dating abuse could predict levels of self-esteem. This model was significant, $F(3,152)=7.650, p<.01$, and accounted for $13.4 \%$ of the variance in self-esteem. As shown in Table 3, gender was a significant predictor of self-esteem, indicating that females reported lower levels of self-esteem than males. Cyber dating abuse was also a significant, negative, predictor of self-esteem and showed that participants who reported higher levels of cyber dating abuse also reported lower levels of self-esteem.

Step 2. The second regression was computed to determine whether cyber dating abuse could significantly predict levels emotional distress as the second step of the mediation model. This model was significant, $F(3,151)$ $=18.54, p<.01$, and accounted for $28 \%$ of the variance in emotional distress. As shown in Table 2, neither age nor gender was a significant predictor of emotional distress. Cyber dating abuse did significantly predict higher levels of emotional distress.

Step 3. A third regression was computed to determine whether emotional distress could be a mediator of cyber dating abuse in predicting self-esteem. Age and gender were entered into the first block of the equation and both cyber dating abuse and emotional distress were added together in the second block. This model was significant, $F(3,151)=10.82, p<.001$, and accounted for $23 \%$ of the variance in self-esteem. As shown in Table 3 , only emotional distress emerged as a significant predictor of self-esteem and cyber dating became nonsignificant when the variables were entered simultaneously. The final model was tested using the bootstrapping method with bias-corrected confidence estimates (MacKinnon et al., 2004; Preacher \& Hayes, 2004). Results of the mediation analysis confirmed the mediating role of emotional distress in the relationship between cyber dating abuse and self-esteem (Table $3, \mathrm{Cl}=-.45--.13$ ). In addition, results indicated that the direct effect of cyber dating abuse became non-significant when controlling for emotional distress, suggesting full mediation. 
Table 3. Regression steps testing the mediation of emotional distress on the relationship between cyber dating abuse and self esteem.

\begin{tabular}{|c|c|c|c|c|}
\hline Variable & Beta (CI) & SE & $t$ & $\begin{array}{l}\text { Variance } \\
\text { accounted }\end{array}$ \\
\hline \multicolumn{5}{|c|}{ Step 1: Predicting Self-Esteem from Cyber Dating Abuse } \\
\hline Age & $.05(-.03 ; .05)$ & .02 & .58 & \\
\hline Gender & $.30(.11 ; .37)$ & .07 & $3.74 * \star$ & $9.2 \%$ \\
\hline Cyber Dating Abuse & $-.20(-.48 ;-.07)$ & .10 & $-2.56^{*}$ & $13.2 \%$ \\
\hline \multicolumn{5}{|c|}{ Step 2: Predicting Emotional Distress from Cyber Dating Abuse } \\
\hline Age & $.10(-.15 ; .03)$ & .04 & .21 & \\
\hline Gender & $-.20(-.09 ; .50)$ & .15 & -.11 & $2.0 \%$ \\
\hline Cyber Dating Abuse & $.51(-2.00 ; 1.14)$ & .21 & $7.19 * *$ & $28.2 \%$ \\
\hline \multicolumn{5}{|c|}{ Step 3: Mediation Model Predicting Self-Esteem from Emotional Distress and Cyber Dating Abuse } \\
\hline Age & $.05(-.02 ; .06)$ & .02 & .67 & \\
\hline Gender & $.30(.11 ; .37)$ & .07 & $3.82 * \star$ & $9.8 \%$ \\
\hline Cyber Dating Abuse & $.001(-.24 ; .24)$ & .12 & .01 & \\
\hline Emotional Distress & $-.36(.08 ; .25)$ & .04 & $-4.24 * \star$ & $22.7 \%$ \\
\hline
\end{tabular}

Note: Age and Gender were entered together in the first block, ${ }^{*} p<.05,{ }^{* *} p<.01$

\section{Discussion}

In line with previous research (Eshelman \& Levendosky, 2012; Hanson, 2002), the results of this study demonstrate the negative relationship between dating abuse and well-being among emerging adults. The results of this study were consistent with our main hypothesis that cyber dating abuse is a significant negative predictor of self-esteem. Furthermore, we found that cyber dating abuse is a significant positive predictor of emotional distress, and that emotional distress fully mediated the relationship between cyber dating abuse in predicting self-esteem. The emotional response that is elicited when partners engage in cyber dating abuse may account for decreased self-esteem.

According to Leary's (1999) Sociometer Theory and Burton et al.'s (2013) Sociolocation Theory, humans have a natural drive to maintain significant relationships. Self-esteem acts as a monitor, searching for cues to determine whether the individual is being accepted or rejected in a relationship. The concept of the sociometer aligns with our notion that it is not necessarily the cyber dating abuse that is directly tied to self-esteem, but rather the emotional distress that occurs when an individual is faced with distrust, criticism, guilt, and anger from pervasive abusive behaviors. Abusive cyber behaviors that are used to monitor a partner's whereabouts signal that they are not a trustworthy partner and devalue their contribution to the relationship. Recipients of cyber dating abuse are at risk for maladjustment because they are likely to make negative interpretations about themselves. This notion of increased emotional distress leading to poorer self-esteem may be similar to other negative mental health outcomes that occur when an individual experiences abuse. It has been found that dating abuse can elicit symptoms related to anxiety, depression, or post-traumatic stress (Hanson, 2002). As such, it is probable that cyber-dating abuse may be linked to other types of disorders as well.

Our results showed that an earlier onset of dating and more frequent relationships are related to both high emotional distress and increased cyber dating abuse. This is in accordance with previous research showing that early onset dating is considered to be a risk factor for negative relationships and interactions (Connolly, Pepler, Craig, \& Taradash, 2000; Hanson, 2002). Emerging adults who are involved in dating relations at a young age may have multiple risk factors for violent dating relationships, including a family history of violence (Olsen, Parra, \& Bennett, 2010). It is possible that younger adolescents may be lacking knowledge or proficiencies to cope with intense dating relationships and all forms of dating abuse. Given that the stability of dating violence among youth into adulthood has been well-documented (Foshee, 1996), school programming that involves education on cyber dating abuse would be beneficial at an early age. 
Although there were no broad level gender differences in the present study, as stated previously, contradicting results have emerged in the field. Some research suggests that women tend to be the perpetrators in verbal and physical aggression (Munoz-Rivas et al., 2007), yet women also report being victimized more often than men (Marquart, Nannini, Edwards, Stanley, \& Wayman, 2007). This study provides support that men and women equally report abuse and their mode of communication technology may only differ marginally. It is likely that each mode of communication could serve a different purpose based on the type of reaction the perpetrator is expecting. For example, sharing a hurtful or insulting comment regarding one's romantic partner on a social media website may receive a different response compared to someone sending a text message, with the exact same content, directly to their partner. This difference in response may vary depending on whether the message is private or public. For example, a public message or comment on Facebook allows the opportunity for others to publicly respond and potentially agree with hurtful or demeaning comments. In contrast, a hurtful or threatening private text message personally attacks and isolates the receiver. In the present study more females reported that a partner used their social networking site without permission. Females are higher consumers of social media (Valenzuela, Park, \& Kee, 2009) suggesting this may be a key method for partners to track their behaviors. However, in previous research, it has been noted that females are more likely to monitor a partner's e-mail accounts and believe that this is acceptable behavior (Burke et al., 2011). This remains an important consideration for future research as it is difficult to make accurate conclusions based on one item.

Our results also show that cyber dating abuse is a frequent issue among youth in our sample. Previous work has found prevalence rates of up to $50 \%-54 \%$ for cyber dating abuse (Borrajo et al., 2015). In the present study, we have found that $10-15 \%$ of youth reported involvement in eight of the areas assessed. One item asking participants about receiving text messages from their partner checking up on them was endorsed by $78 \%$ of the sample. This item clearly reflects a common behavior among dating couples, which may not always signify dating abuse and may reflect both controlling and friendly behaviors. Despite this ambiguity, there is evidence that even vaguely hurtful behaviors could provoke anxiety or criticism and have harmful effects (Madlock \& Westerman, 2011). One important consideration with ambiguous behaviors in the dating context may involve frequency. Checking-in on a partner once a day is quite different than checking-in every hour and may lead to a different interpretation of the partner's motivations (Alexy, Burgess, Baker, \& Smoyak, 2005). Moreover, there may be developmental differences in the victim's interpretation of these behaviors.

\section{Study Limitations and Implications}

Given the correlational nature of this study, it is difficult to determine the temporal ordering of abuse, emotional distress, and self-esteem. It is important to note that ruminating on one's emotional distress may be perpetuating, as opposed to triggering, lowered self-esteem. Much like the cyclical nature of abuse, the process of cyber dating abuse is a continuous one, where the repetition of the negative message is related to the intensity of emotional distress (Temple et al., 2016). Self-verification theory (Swann, 1983) posits that individuals with low self-esteem may be drawn to partners who abuse and mistreat them, as they prefer feedback that confirms their pre-existing negative self-views. The concern is that, due to this desire for self-verification, individuals with low self-esteem would remain in an abusive relationship. This concern was explored in research by Katz, Street, and Arias (1997), which found that women with low self-esteem who attribute the cause of their partner's violence to themselves are more likely to forgive their partner and maintain the abusive relationship.

Although the correlation of cyber dating abuse and self-esteem may be partially explained by emotional distress, it is possible that psychological abuse can also share this same relationship. Psychological abuse is a form of mistreatment that involves mental or emotional pain or injury, which can include, but is not limited, to verbal aggression (i.e., statements intended to humiliate, insult, or threaten an individual; O'Leary \& Maiuro, 2004). Thus, psychological abuse and cyber dating abuse share many of the same methods of presentation, such as: relational aggression, demeaning language, and threatening behaviors. In fact, studies have shown that cyber dating abuse is related to offline dating abuse, particularly psychological abuse (Borrajo et al., 2015; Zweig et al., 2013). Cyber dating abuse could also encompass many types of abuse, including sexual and verbal acts of aggression. It remains to be determined whether the medium through which these behaviors are expressed, such as phones and computers, has any additive effect on adjustment. Future studies should assess the relative contribution of cyber dating abuse to more traditional measures. 
Another point for consideration is the dyadic nature of the romantic relationship context. It would be worthwhile to consider the factors that contribute to self-esteem of both partners in a relationship and how this may change over time. Robinson and Cameron (2012) found an additive effect within dating relationships, such that both partner's self-esteem levels combine in order to determine relationship quality. Similarly, there is considerable overlap in both victimization and perpetration and each partner is likely to experience some level of retaliation. Thus, the overall volatility of the relationship will also have consequences for adjustment.

Finally, although efforts were made to encourage equal participation, there was significant discrepancy in the number of males versus females that participated in the study. As participants were recruited on a voluntary basis, it was difficult to control this discrepancy. Therefore, any speculations made involving gender should take this into account. The sample was also drawn from a population of first-year undergraduate university students, which may limit the generalizability of the results. For example, as the participants were recruited from a lowrisk population, it is possible that well-adjusted university students are less likely to experience dating violence.

\section{Conclusion}

In summary, the present study shows that cyber dating abuse is negatively related to self-esteem among emerging adults. Only recently have researchers interested in dating violence begun to study cyber dating abuse as a separate category of behavior, and the majority of studies to date are descriptive in nature. We have shown that emerging adults who report cyber dating abuse also experience emotional distress and lowered selfesteem, possibly as a consequence of these controlling behaviors. Moreover, the relative number of youth who report abusive cyber behaviors is comparable to other studies on cyber dating abuse (Zweig et al., 2013; Melander, 2010). With these results in mind, current programs aimed at the prevention of dating abuse should be careful to incorporate information specific to cyber dating abuse.

\section{References}

Aiken, L. S., \& West, S. G. (1991). Multiple regression: Testing and interpreting interactions. Newbury Park: Sage.

Alexy, E., Burgess, A., Baker, T., \& Smoyak, S. (2005). Perceptions of cyberstalking among college students. Brief Treatment and Crisis Intervention, 5, 279-289.

Arnett, J. J. (2000). Emerging adulthood: A theory of development from the late teens through the twenties. American Psychologist, 55, 469-480.

Baron, R. M., \& Kenny, D. A. (1986). The moderator-mediator variable distinction in social psychological research: Conceptual, strategic and statistical considerations. Journal of Personality and Social Psychology, 51, 1173-1182. https://doi.org/10.1037/0022-3514.51.6.1173

Borrajo, E., Gamez-Guadix, M., \& Calvete, E. (2015). Cyber dating abuse: Prevalence, context, and relationship with offline dating aggression. Psychological Reports: Relationships \& Communications, 116, 565-585.

https://doi.org/10.2466/21.16.PR0.116k22w4

Burke, S. C., Wallen, M., Vail-Smith, K., \& Knox, D. (2011). Using technology to control intimate partners: An exploratory study of college undergraduates. Computers in Human Behavior, 27, 1162-1167.

https://doi.org/10.1016/j.chb.2010.12.010

Burton, C. W., Halpern-Felsher, B., Rehm, R. S., Rankin, S., \& Humphreys, J. C. (2013). "It was pretty scary": The theme of fear in young adult women's descriptions of a history of adolescent dating abuse. Issues in Mental Health Nursing, 34, 803-813. https://doi.org/10.3109/01612840.2013.827286

Collins, W. A., Welsh, D. P., \& Furman, W. (2009). Adolescent romantic relationships. Annual Review of Psychology, 60, 631-652. https://doi.org/10.1146/annurev.psych.60.110707.163459

Connolly, J., Pepler, D. J., Craig, W. M., \& Taradash, A. (2000). Dating experiences of bullies in early adolescence. Child Maltreatment, 4, 299-310. https://doi.org/10.1177/1077559500005004002 
Dick, R., N., McCauley, H. L., Jones, K. A., Tancredi, D., Goldstein, S., Blackburn, S., . . Miller, E. (2014). Cyber dating abuse among teens using school-based health centers. Pediatrics, 134, 1560-1567.

https://doi.org/10.1542/peds.2014-0537

Downey, G., \& Feldman, S. I. (1996). Implications of rejection sensitivity for intimate relationships. Journal of Personality and Social Psychology, 70, 1327-1343. https://doi.org/10.1037/0022-3514.70.6.1327

Ellis, W. E., Crooks, C. V., \& Wolfe, D. A. (2009). Relational aggression in peer and dating relationships: Links to psychological and behavioral adjustment. Social Development, 18, 253-269. https://doi.org/10.1111/j.14679507.2008.00468.x

Eshelman, L., \& Levendosky, A. A. (2012). Dating violence: Mental health consequences based on type of abuse. Violence and Victims, 27, 215-228. https://doi.org/10.1891/0886-6708.27.2.215

Foshee, V. A. (1996). Gender differences in adolescent dating abuse prevalence, types and injuries. Health Education Research, 11, 275-286. https://doi.org/10.1093/her/11.3.275-a

Göncü, A., \& Sümer, N. (2011). Rejection sensitivity, self-esteem instability, and relationship outcomes the mediating role of responsibility attributions. European Psychologist, 16, 303-313. https://doi.org/10.1027/10169040/a000066

Hanson, R. F. (2002). Adolescent dating violence: Prevalence and psychological outcomes. Child Abuse \& Neglect, 26, 447-451. https://doi.org/10.1016/S0145-2134(02)00321-6

Iconis, R. (2013). Dating violence among college students. Contemporary Issues in Education Research, 6, 111-114. https://doi.org/10.19030/cier.v6i1.7609

Jouriles, E. N., Garrido, E., Rosenfield, D., \& McDonald, R. (2009). Experiences of psychological and physical aggression in adolescent romantic relationships: Links to psychological distress. Child Abuse and Neglect, 33, 451460. https://doi.org/10.1016/j.chiabu.2008.11.005

Katz, J., Arias, I., \& Beach, S. R. H. (2000). Psychological abuse, self-esteem, and women's dating relationship outcomes: A comparison of the self-verification and self-enhancement perspectives. Psychology of Women Quarterly, 24, 34-35. https://doi.org/10.1111/j.1471-6402.2000.tb00217.x

Katz, J., Street, A., \& Arias, I. (1997). Individual differences in self-appraisals and responses to dating violence scenarios. Violence and Victims, 12, 265-276.

Kaukinen, C. (2014). Dating violence among college students: The risk and protective factors. Trauma, Violence, \& Abuse, 15, 283-296. https://doi.org/10.1177/1524838014521321

Korchmaros, J. D., Ybarra, M. L., Langhinrichsen-Rohling, J., Boyd, D., \& Lenhart, A. (2013). Perpetration of teen dating violence in a networked society. Cyberpsychology, Behavior, and Social Networking, 16, 561-567. https://doi.org/10.1089/cyber.2012.0627

Leary, M. R. (1999). Making sense of self-esteem. Current Directions in Psychological Science, 8, 32-35. https://doi.org/10.1111/1467-8721.00008

Leary, M. R., \& Baumeister, R. F. (2000). The nature and function of self-esteem: Sociometer theory. Advances in Experimental Social Psychology, 32, 1-62. https://doi.org/10.1016/s0065-2601(00)80003-9

Leary, M. R., Tambor, E. S., Terdal, S. J., \& Downs, D. L. (1995). Self-esteem as an interpersonal monitor: The sociometer hypothesis. Journal of Personality and Social Psychology, 68, 518-530. https://doi.org/10.1037/00223514.68.3.518

Liu, W., Yu, B., \& Ma, Y. (2014). Educational and skills-based interventions for preventing relationship and dating violence in adolescents and young adults. Public Health Nursing, 31, 441-443. https://doi.org/10.1111/phn.12115

Longmore, M. A., \& Demaris, A. (1997). Perceived inequity and depression in intimate relationships: The moderating effect of self-esteem. Social Psychology Quarterly, 60, 172-184. https://doi.org/10.2307/2787103

MacKinnon, D. P., Lockwood, C. M., \& Williams, J. (2004). Confidence limits for the indirect effect: Distribution of the product and resampling methods. Multivariate Behavioral Research, 39, 99-128.

https://doi.org/10.1207/s15327906mbr3901_4 
Madlock, P. E., \& Westerman, D. (2011). Hurtful cyber-teasing and violence: Who's laughing out loud? Journal of Interpersonal Violence, 26, 3542-3560. https://doi.org/10.1177/0886260511403749

Marcus, R. F. (2004). Dating partners' responses to simulated dating conflict: Violence chronicity, expectations, and emotional quality of relationship. Genetic, Social, and General Psychology Monographs, 130, 163-188. https://doi.org/10.3200/MONO.130.2.163-192

Marquart, B., Nannini, D., Edwards, R., Stanley, L., \& Wayman, J. (2007). Prevalence of dating violence and victimization: Regional and gender differences. Adolescence, 42, 645-657.

Melander, L. A. (2010). College students' perceptions of intimate partner cyber harassment. Cyberpsychology, Behavior, and Social Networking, 13, 263-268. https://doi.org/10.1089/cyber.2009.0221

Munoz-Rivas, M. J., Gómez, J. L. G., O'Leary, K., \& Lozano, P. G. (2007). Aggression in adolescent dating relationships: Prevalence, justification, and health consequences. Journal of Adolescent Health, 40, 298-304. https://doi.org/10.1016/j.jadohealth.2006.11.137

National Centre of Injury Prevention and Control: Division of Violence Prevention. (2016). Understanding teen dating violence. Retrieved from https://www.cdc.gov/violenceprevention/pdf/Retrieved from https://www.cdc.gov/violenceprevention/pdf/teen-dating-violence-factsheet-a.pdf

O'Leary, K., \& Maiuro, R. (2004). Psychological abuse in violent domestic relationships. New York, NY: Springer Publishing Company, Inc.

Olsen, J. P., Parra, G. R., \& Bennett, S. A. (2010). Predicting violence in romantic relationships during adolescence and emerging adulthood: A critical review of the mechanisms by which familial and peer influences operate. Clinical Psychology Review, 30, 411-422. https://doi.org/10.1016/j.cpr.2010.02.002

Orpinas, P., Hsieh, H. L., Song, X., Holland, K., \& Nahapetyan, L. (2013). Trajectories of physical dating violence from middle to high school: Association with relationship quality and acceptability of aggression. Journal of Youth and Adolescence, 42, 551-565. https://doi.org/10.1007/s10964-012-9881-5

Patchin, J. W., \& Hinduja, S. (2010). Cyberbullying and self-esteem. Journal of School Health, 80, 614-621. https://doi.org/10.1111/j.1746-1561.2010.00548.x

Picard, P. (2007). Tech abuse in teen relationships study. Teen Research Unlimited. Retrieved from http://www.loveisrespect.org/wp-content/uploads/2009/03/liz-claiborne-2007-tech-relationship-abuse.pdf.

Pierce, G. R., Sarason, I. G., \& Sarason, B. R. (1991). General and relationship-based perceptions of social support: Are two constructs better than one? Journal of Personality and Social Psychology, 61, 1028-1039.

https://doi.org/10.1037/0022-3514.61.6.1028

Preacher, K. J., \& Hayes, A. F. (2004). SPSS and SAS procedures for estimating indirect effects in simple mediation models. Behavior Research Methods, Instruments, and Computers, 36, 717-731.

https://doi.org/10.3758/BF03206553

Preacher, K. J., \& Hayes, A. F. (2008). Asymptotic and resampling strategies for assessing and comparing indirect effects in multiple mediator models. Behavior Research Methods, 40, 879-891.

https://doi.org/10.3758/BRM.40.3.879

Rill, L., Baiocchi, E., Hopper, M., Denker, K., \& Olson, L. N. (2009). Exploration of the relationship between selfesteem, commitment, and verbal aggressiveness in romantic dating relationships. Communication Reports, 22 , 102-113. https://doi.org/10.1080/08934210903061587

Robinson, K. J., \& Cameron, J. J. (2012). Self-esteem is a shared relationship resource: Additive effects of dating partners' self-esteem levels predict relationship quality. Journal of Research in Personality, 46, 227-230.

https://doi.org/10.1016/j.jrp.2011.12.002

Rosenberg, M. (1965). Society and the adolescent self-image. Princeton, NJ: Princeton University Press. 
Rusbult, C. (1980). Commitment and satisfaction in romantic relationships: A test of the investment model. The Journal of Experimental and Social Psychology, 16, 172-186. https://doi.org/10.1016/0022-1031(80)90007-4

Rusbult, C., \& Martz, J. (1995). Remaining in an abusive relationship: An investment model analysis of nonvoluntary dependence. Personality and Social Psychology Bulletin, 21, 558-571.

https://doi.org/10.1177/0146167295216002

Sawangchareon, K., Wattananukulkiat, S., Saito, A. S., Nanakorn, S., Doasodsai, S., Baba, M., ... Takemoto, H. (2013). The impact of counseling on the self-esteem of women in Thailand who have experienced intimate partner violence. International Journal of Caring Sciences, 6, 243-251.

Smetana, J. G., Campione-Barr, N., \& Metzger, A. (2006). Adolescent development in interpersonal and societal contexts. Annual Review of Psychology, 57, 255-284. https://doi.org/10.1146/annurev.psych.57.102904.190124

Stader, D. L. (2011). Dating violence. The Clearing House: A Journal of Educational Strategies, Issues and Ideas, 84, 139-143. https://doi.org/10.1080/00098655.2011.564980

Swann, W. B., Jr. (1983). Self-verification: Bringing social reality into harmony with the self. In J. Suls \& A. G. Greenwald (Eds.), Social Psychology Perspectives (Vol. 2, pp. 33-66). Hillsdale, NJ: Erlbaum.

Temple, J. R., Chio, H. J., Brem, M., Wolford-Clevenger, C., Stuart, G. L., Peskin M. F., Elmquist, J. (2016). The temporal association between traditional and cyber dating abuse among adolescence. Journal of Youth and Adolescence, 45, 340-349. https://doi.org/10.1007/s10964-015-0380-3

Valenzuela, S., Park, N., \& Kee., K. (2009). Is there social capital in a social network site?: Facebook use and college students' life satisfaction, trust and participation. Journal of Computed-Mediate Communication, 14, 875-901. https://doi.org/10.1111/j.1083-6101.2009.01474.x

Wright, M. F. (2015). Cyber aggression within adolescents' romantic relationships: Linkages to parental and partner attachment. Journal of Youth and Adolescence, 44, 37-47. https://doi.org/10.1007/s10964-014-0147-2

Zweig, J. M., Dank, M., Yahner, J., \& Lachman, P. (2013). The rate of cyber dating abuse among teens and how it relates to other forms of teen dating violence. Journal of Youth and Adolescence, 42, 1063-1077.

https://doi.org/10.1007/s10964-013-9922-8

Zweig, J. M., Lachman, P., Yahner, J., \& Dank, M. (2014). Correlates of cyber dating abuse among teens. Journal of Youth and Adolescence, 43, 1306-132. https://doi.org/10.1007/s10964-013-0047-x

\section{Correspondence to:}

Wendy Ellis

King's University College at Western University

266 Epworth Ave, London, ON

Canada N6A $2 \mathrm{M} 3$

Email: wendy.ellis(at)uwo.ca

\section{About Authors}

Kaitlin Hancock began this project when she was an undergraduate student at King's University College.

Haley Keast began this project when she was an undergraduate student at King's University College.

Wendy Ellis is an associate professor at King' University College. Her research interests are in the area of dating abuse, bullying and other risk-taking behaviors among children and emerging adults.

Editorial record: First submission received on May 18, 2016. Revision received on January 18, 2017. Accepted for publication on April 18, 2017. 